\title{
Can vaginal ultrasound replace diagnostic curettage in the detection of endometrial pathology in post-menopausal bleeding?
}

\begin{abstract}
Received: 11/ 1/ 2018
Accepted: $16 / 8 / 2018$

\begin{tabular}{cccc}
\hline Media Ghazi Sedeq $^{1 *}$ & Shawnam Nasih Dawood $^{1}$ & Aska Farooq $^{1}$ & Shahla K. Alalaf $^{2}$ \\
\hline Abstract &
\end{tabular}

Background and objective: Post-menopausal bleeding due to endometrial abnormalities is a common diagnostic challenge facing the ultrasonogists and referring gynecologists. This study aimed to detect the validity of transvaginal ultrasound to detect endometrial pathologies and its sensitivity and specificity for determining endometrial carcinoma in women with postmenopausal bleeding.

Methods: A diagnostic accuracy study of transvaginal ultrasound and diagnostic curettage was conducted for evaluation of endometrial pathology in the College of Medicine, Hawler Medical University from October2016to January 2018. The sample size included 55 women with post-menopausal vaginal bleeding. The ultrasound findings were compared with histopathological results of endometrial biopsy.

Results: Out of 55 women, $49.09 \%$ had endometrial atrophy, $29.09 \%$ had endometrial hyperplasia, $16.36 \%$ had endometrial polyp, $3.64 \%$ had endometrial carcinoma, and $1.82 \%$ had hyperplasia with atypia according to histopathological findings. The sensitivity of ultrasound in detecting cancer was $66.7 \%$, the specificity was $100 \%$, the positive predictive value (PV) was $100 \%$, and the negative predictive value was $98.1 \%$. The total agreement rate was $98.2 \%$.

Conclusion: Transvaginal ultrasound is an excellent diagnostic tool to determine whether further investigation with histopathological examination of endometrial biopsy is necessary for postmenopausal vaginal bleeding.
\end{abstract}

Keywords: Transvaginal ultrasound; Postmenopausal bleeding; Endometrial pathology.

\section{Introduction}

Postmenopausal bleeding refers to vaginal bleeding that occurs after twelve months of amenorrhea in a woman of the age where the menopause can be expected. ${ }^{1}$ It can also be defined as the time in a woman's life when the woman stops having a menstrual period permanently and is no longer fertile. ${ }^{2}$ However, it can be applied to younger women following premature ovarian failure or premature menopause. ${ }^{3}$ Vaginal bleeding is a common post menopausal complaint representing $5 \%$ of all gynecology outpatient consultations. ${ }^{4}$ The incidence of postmenopausal bleeding is $10 \%$ in the general population immediately after menopause. ${ }^{5}$ The causes of postmenopausal bleeding include endometrial atrophy (approximately $75 \%$ of cases), ${ }^{3}$ endometrial polyps, submucosal fibroids, endometrial hyperplasia (simple, complex and atypical), endometrial carcinoma (approximately 10\%), and estrogen withdrawal. $^{6}$ Non-gynecological causes include trauma, systemic diseases like hypertension, hypothyroidism, and bleeding disorders. ${ }^{3}$ Endometrial abnormalities are common diagnostic challenges facing the radiologist and referring specialist gynecologist. Ultrasound is the primary imaging modality in this workup; findings if further investigations done like sonohysterography, hysterosalpingography, magnetic resonance imaging, and computed tomography are often correlated

${ }^{1}$ Department of Surgery, College of Medicine, Hawler Medical University, Erbil, I raq.

2 Department of Obstetrics and Gynaecology, College of Medicine, Hawler Medical University, Erbil, I raq.

* Correspondence: media.ghazi@hmu.edu.krd 
with ultrasound findings. In the last decades, transvaginal ultrasound has become widely used in the evaluation of women with postmenopausal bleeding. transvaginal ultrasound was introduced in the early 1990s, a strategy with transvaginal ultrasound as the initial investigation, the possibility of endometrial abnormalities strongly reduced, and further evaluation with diagnostic curettage is according to the ultrasound results. ${ }^{7}$ The normal postmenopausal endometrium is thin, echogenic, regular and homogeneous. There is controversy regarding postmenopausal endometrial thickness, some authors have found that endometrial thickness decreases with increasing age, ${ }^{6}$ in general, a double-layer thickness of less than $5 \mathrm{~mm}$ without focal thickening excludes significant disease and is consistent with endometrial atrophy. 6,8 The mean postmenopausal endometrial thickness is thinner than in premenopausal women. Thickening of the endometrium may indicate the presence of pathology. In general, the thicker the endometrium, the higher the likelihood of important pathology, i.e., endometrial cancer being present. The threshold in the UK is $5 \mathrm{~mm}$; a thickness of $>5 \mathrm{~mm}$ gives $7.3 \%$ likelihood of endometrial cancer. ${ }^{9}$ In a woman with postmenopausal bleeding, if the endometrial thickness is less than $5 \mathrm{~mm}$ uniformly, the probability of carcinoma is less than $1 \%{ }^{10,11}$ transvaginal ultrasound demonstrates the type of abnormality seen within the endometrial cavity. ${ }^{10}$ For example, endometrial hyperplasia, polyps, or carcinoma. Classically, endometrial hyperplasia affects the entire endometrium and results in thickening of the endometrium. ${ }^{10}$ All types of endometrial hyperplasia (cystic, adenomatous, atypical) can cause diffuse smooth or, less commonly, focal hyperechoic endometrial thickening. Endometrial hyperplasia is considered whenever the endometrium appears to exceed $5 \mathrm{~mm}$ in thickness. ${ }^{6}$ Endometrial polyps manifest as focal areas of endometrial thickening, on vaginal sonography they appear as a hyperechoic lesion with a regular outline. The polyp may be broad-based and sessile or pedunculated, and the stalk of the polyp may be seen if sufficient fluid is present in the endometrial cavity. ${ }^{12}$ The finding of a single feeding vessel or single vascular stalk to a suspected polyp has been demonstrated to confirm the presence of a polyp with a specificity and negative predictive value of $95 \%$ and $94 \%$ respectively. ${ }^{13}$ Endometrial carcinoma may occur in the form of a polyp, within endometrial hyperplasia, or as a heterogeneous endometrial mass with a widened irregular cavity, other ultrasound features of endometrial carcinoma include heterogeneity and irregular endometrial thickening. These signs are nonspecific and can be seen in endometrial hyperplasia as well as polyps. However, polypoid tumors cause more diffuse and irregular thickening than a polyp and more heterogeneity than endometrial hyperplasia. A more specific ultrasound sign is irregularity of the endometriummyometrium border, a finding that indicates invasive disease and usually cancer are highly vascular with many supplying vessels. ${ }^{6,10}$ Pathological confirmation of the histology is needed in all cases. Endometrial biopsy is performed if the endometrial cavity is irregular, the endometrium has diffuse or focal widening greater than $5 \mathrm{~mm}$, or if the whole endometrium has not been adequately assessed. ${ }^{1,10}$ Although endometrial cancer accounts for $6 \%$ of all female cancers, it causes only about $3 \%$ of all cancerrelated deaths. This study aimed to see whether transvaginal ultrasound can replace diagnostic curettage in the detection of endometrial pathologies in post- menopausal bleeding and to find the sensitivity and specificity of transvaginal ultrasound in the detection of endometrial carcinoma in postmenopausal women with bleeding. 


\section{Methods}

This was a prospective diagnostic accuracy study done in the College of Medicine, Hawler Medical University from October 2016 to January 2018. The study included 55 women with post-menopausal vaginal bleeding. The transvaginal ultrasound findings of the endometrium were compared with histopathological results of endometrial biopsy using dilatation and curettage (D\&C). The exclusion criteria were women on hormone-replacement therapy, diabetic and hypertensive patients, those with blood disorders and patients with vaginal pathologies or pelvic masses whether ovarian or uterine. The study was approved by the Research Ethics Committee of the College of Medicine, Hawler Medical University. A written informed consent was obtained from each participant in the study. Vaginal ultrasound and D\&C procedures were explained to the patients. The ultrasound examinations were made by an experienced radiologist in a private clinic using General Electric (GE), Voluson 6, endo-vaginal transducer $\mathrm{E}$ 8-MHZ. It was performed after asking the woman to empty her bladder, and she was asked to undress from the waist down, lie in a dorsal position on the examination couch, a sheet was provided to cover her. She was asked to bend her legs. The probe was cleaned and covered with a plastic or latex sheath after the gel has been placed on the transducer tip. Then, the transducer was inserted into the vagina. The sound beam was directed by rotating and angling the probe from anterior to posterior and sliding it in and out and transverse and longitudinal sections of the endometrium were obtained. The endometrium was analyzed for morphology, outline, thickness, vascularity, endometrial-myometrial junction, focal abnormality, texture, and the presence of fluid or masses in the cavity. The thickest part of the endometrium was obtained, and maximum endometrial thickness in the sagittal plane was measured from echogenic to the echogenic border. The adjacent hypoechoic myometrium and fluid in the cavity were not included. In the presence of endometrial fluid, the measurement of the two separate layers of the endometrium, excluding the fluid, were added to determine the endometrial thickness, endometrial abnormalities reported were they found, endometrial atrophy was diagnosed when a doublelayer thickness of equal or less than $5 \mathrm{~mm}$ without focal thickening. ${ }^{9}$ Endometrial hyperplasia was diagnosed when there was regular generalized diffuse thickening of entire endometrial cavity exceeding $5 \mathrm{~mm}$. Endometrial polyp was diagnosed or suggested when there wasa focal hyperechoic thickening of endometrial cavity and having a single vascular stalk or feeding vessel using color Doppler ultrasound. During assessing the endometrial cavity, endometrial carcinoma was suggested when there was irregular and heterogeneous thickening of endometrial cavity. More specific sign was abnormal high vascularity of irregularly thickened area, but only color Doppler was used. After each scanning, the transducer was withdrawn gently toward fornix to avoid discomfort to the patient, and the probe was cleaned. Patients were referred to Erbil Maternity Hospital for dilation and curettage, which was conducted in the theater by specialist gynecologist under general anesthesia according to the hospital regulations. Specimens were sent for histopathological examination and interpreted by specialist pathologists.

\section{Statistical analysis}

Data were analyzed using the statistical package for the social sciences (version 22). Frequencies and percentages were calculated. McNemar test was used (in the 2X2 tables) when the results of ultra-sound were compared with the histopathological findings (of the same patients); as in the following table: 
https:/ / doi.org/ 10.15218/ zjms.2019.029

\begin{tabular}{lccc}
\hline $\begin{array}{l}\text { Ultrasound } \\
\text { findings }\end{array}$ & \multicolumn{2}{c}{$\begin{array}{c}\text { Histo-pathological findings } \\
\text { Positive }\end{array}$} & $\begin{array}{c}\text { P value } \\
\text { (By } \\
\text { McNemar) }\end{array}$ \\
\hline Positive & TP & FP & \\
Negative & FN & TN & \\
Total & TP+FN & FP+TN & \\
\hline
\end{tabular}

$\mathrm{TP}=$ True positive; $\mathrm{TN}=$ True negative;

$\mathrm{FP}=$ False positive; $\mathrm{FN}=$ False negative.

Sensitivity $=$ TP $/(T P+F N)^{*} 100$.

Specificity $=\mathrm{TN} /(\mathrm{FP}+\mathrm{TN}){ }^{*} 100$.

$P$ value $\leq 0.05$ was considered statistically significant.

\section{Results}

The mean age of the participants $\pm S D$ was $58.42 \pm 4.4$ years, ranging from 50 to
70 years, and the median age was 58 years. Table 1 shows that the highest proportion of the patients $(47.3 \%)$ were in the age range of $55-59$ years. Only $12.7 \%$ aged 65 years or more. Results of transvaginal ultrasound showed that $49.1 \%$ of the women had normal thin endometrium, $20 \%$ had thick regular endometrium, $16.4 \%$ had polyp, and $14.5 \%$ had thick irregular endometrium. Endometrial carcinoma was suspected in two out of eight patients with thick irregular endometrium depending on vascularity, and disturbance of endometrial-myometrial junction. Details are shown in Table 2, Figures 1 and 2.

Table 1: Age distribution of the studied sample.

\begin{tabular}{lcc}
\hline Age (years) & No. & $\%$ \\
\hline $50-54$ & 9 & 16.4 \\
$55-59$ & 26 & 47.3 \\
$60-64$ & 13 & 23.6 \\
$\geq 65$ & 7 & 12.7 \\
Total & 55 & 100.0 \\
\hline
\end{tabular}

Table 2: Distribution of the studied sample by transvaginal ultrasound findings.

\begin{tabular}{lcc}
\hline Ultrasound findings & No. & $\%$ \\
\hline Normal thin endometrium (atrophic endometrium) & 27 & 49.1 \\
Polyp & 9 & 16.4 \\
Thick regular (suggestive of hyperplasia) & 11 & 20.0 \\
Thick irregular*(complex hyperplasia) & 8 & 14.5 \\
Total & 55 & 100.0 \\
\hline
\end{tabular}



Figure 1: 51 year-old woman with postmenopausal bleeding transvaginal sagittal ultrasound shows atrophic endometrium that measures $2 \mathrm{~mm}$ (arrowheads).



Figure 2: Transvaginal ultrasound showing a thick endometrial cavity with hyperechoic mass inside suggestive of a polyp. 
The histopathological examination showed that $49.1 \%$ of the women had atrophic endometrium. Others diagnosed as having simple endometrial hyperplasia $(16.4 \%)$, polyp (16.4\%), and complex hyperplasia $(10.9 \%)$, as shown in Table 3. Table 4 shows complete agreement between transvaginal ultrasound and histopathological findings regarding the detection (diagnosis) of normal endometrium (27 cases), polyp (9 cases), and cancer ( 2 cases). Seventeen cases were diagnosed as hyperplasia by ultrasound; $52.9 \%$ of them found to have simple endometrial hyperplasia according to the histopathological results, and $35.3 \%$ had complex hyperplasia.

Table 3: Distribution of the studied sample by histopathological diagnosis.

\begin{tabular}{lcc}
\hline Histopathology results & No. & $\%$ \\
\hline Atrophic endometrium & 27 & 49.1 \\
Hyperplasia with atypia & 1 & 1.8 \\
Simple endometrial hyperplasia & 9 & 16.4 \\
Polyp & 9 & 16.4 \\
Endometrial carcinoma & 2 & 3.6 \\
Complex endometrial hyperplasia & 6 & 10.9 \\
Chronic endometritis & 1 & 1.8 \\
Total & 55 & 100.0 \\
\hline
\end{tabular}

Table 4: Comparison between transvaginal ultrasound and histopathological findings.

\begin{tabular}{|c|c|c|c|c|c|c|c|c|}
\hline & & & sto-pat & logical $f$ & idings & & & \\
\hline & 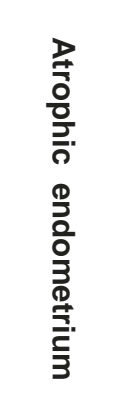 & 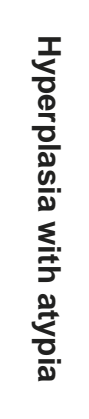 & 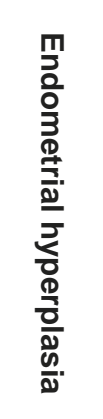 & 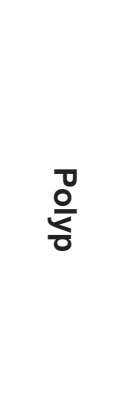 & 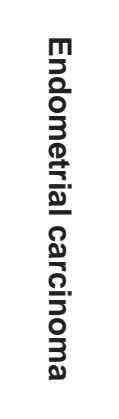 & 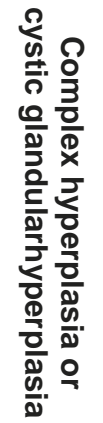 & 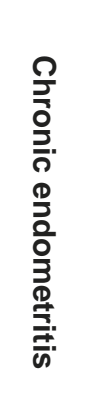 & o- \\
\hline $\begin{array}{l}\text { Transvaginal ultrasound } \\
\text { findings }\end{array}$ & $\begin{array}{l}\text { No. } \\
\text { (\%) }\end{array}$ & $\begin{array}{l}\text { No. } \\
(\%)\end{array}$ & $\begin{array}{l}\text { No. } \\
\text { (\%) }\end{array}$ & $\begin{array}{l}\text { No. } \\
\text { (\%) }\end{array}$ & $\begin{array}{l}\text { No. } \\
\text { (\%) }\end{array}$ & $\begin{array}{l}\text { No. } \\
(\%)\end{array}$ & $\begin{array}{l}\text { No. } \\
(\%)\end{array}$ & $\begin{array}{l}\text { No. } \\
\text { (\%) }\end{array}$ \\
\hline $\begin{array}{l}\text { Normal thin } \\
\text { endo-metrium }\end{array}$ & $\begin{array}{c}27 \\
(100.0)\end{array}$ & $\begin{array}{c}0 \\
(0.0)\end{array}$ & $\begin{array}{c}0 \\
(0.0)\end{array}$ & $\begin{array}{c}0 \\
(0.0)\end{array}$ & $\begin{array}{c}0 \\
(0.0)\end{array}$ & $\begin{array}{c}0 \\
(0.0)\end{array}$ & $\begin{array}{c}0 \\
(0.0)\end{array}$ & $\begin{array}{c}27 \\
(100.0)\end{array}$ \\
\hline Polyp & $\begin{array}{c}0 \\
(0.0)\end{array}$ & $\begin{array}{c}0 \\
(0.0)\end{array}$ & $\begin{array}{c}0 \\
(0.0)\end{array}$ & $\begin{array}{c}9 \\
(100.0)\end{array}$ & $\begin{array}{c}0 \\
(0.0)\end{array}$ & $\begin{array}{c}0 \\
(0.0)\end{array}$ & $\begin{array}{c}0 \\
(0.0)\end{array}$ & $\begin{array}{c}9 \\
(100.0)\end{array}$ \\
\hline Hyperplasia & $\begin{array}{c}0 \\
(0.0)\end{array}$ & $\begin{array}{c}1 \\
(5.9)\end{array}$ & $\begin{array}{c}9 \\
(52.9)\end{array}$ & $\begin{array}{c}0 \\
(0.0)\end{array}$ & $\begin{array}{c}0 \\
(0.0)\end{array}$ & $\begin{array}{c}6 \\
(35.3)\end{array}$ & $\begin{array}{c}1 \\
(5.9)\end{array}$ & $\begin{array}{c}17 \\
(100.0)\end{array}$ \\
\hline Cancer & $\begin{array}{c}0 \\
(0.0)\end{array}$ & $\begin{array}{c}0 \\
(0.0)\end{array}$ & $\begin{array}{c}0 \\
(0.0)\end{array}$ & $\begin{array}{c}0 \\
(0.0)\end{array}$ & $\begin{array}{c}2 \\
(100.0)\end{array}$ & $\begin{array}{c}0 \\
(0.0)\end{array}$ & $\begin{array}{c}0 \\
(0.0)\end{array}$ & $\begin{array}{c}2 \\
(100.0)\end{array}$ \\
\hline Total & $\begin{array}{c}27 \\
(49.1)\end{array}$ & $\begin{array}{c}1 \\
(1.8)\end{array}$ & $\begin{array}{c}9 \\
(16.4)\end{array}$ & $\begin{array}{c}9 \\
(16.4)\end{array}$ & $\begin{array}{c}2 \\
(3.6)\end{array}$ & $\begin{array}{c}6 \\
(10.9)\end{array}$ & $\begin{array}{c}1 \\
(1.8)\end{array}$ & $\begin{array}{c}55 \\
(100.0)\end{array}$ \\
\hline
\end{tabular}


Table 5a presents results of transvaginal ultrasound and histopathology of the same patients. The sensitivity of ultrasound in detecting endometrial carcinoma was $66.7 \%$, the specificity was $100 \%$, the predictive value (PV) positive was $100 \%$, and the PV negative was $98.1 \%$. The total agreement rate was $98.2 \%$ as presented in Table 5b.

\section{Discussion}

Post-menopausal bleeding is a significant symptom that requires special concern because it may be the only clinical manifestation of endometrial carcinoma, which is regarded as the most common gynecological malignancies. It is the fourth most common cancer in western countries, and it is the commonest malignancy of the female genital tract in developed countries. Unlike other malignancies, endometrial cancer because of early presentation with vaginal bleeding when diagnosed in early stage, there is a possibility of curative treatment by hysterectomy. In contrast, with increased staging, the survival decreases. ${ }^{14}$ Gynecologists have long approached postmenopausal bleeding as "endometrial cancer until proved otherwise. Endometrial pathologies whether benign or malignant are common causes of postmenopausal bleeding; $90 \%$ of women with endometrial cancer present with postmenopausal bleeding. ${ }^{3}$ Vaginal sonography is the first line of investigation or approach in postmenopausal bleeding, and it is preferred over biopsy because it is a painless, inexpensive, less invasive procedure to visualize endometrial cavity with no complications, high negative predictive values and it may be more sensitive for detecting endometrial carcinoma than a blind biopsy. Timmermans et al. found that transvaginal ultrasonography is the first line test in the assessment of postmenopausal bleeding. ${ }^{15}$ The present study revealed that the mean age of patients was 58.42 years; the majority of patients presented with postmenopausal bleeding were in the age group 55-59 years, while El-Mowali et al. observed the mean age in Egypt women having postmenopausal bleeding was 52.6 years, range $48-56$ years. ${ }^{16}$ The current study revealed that the commonest cause of uterine bleeding is endometrial atrophy. The majority of patients with postmenopausal vaginal bleeding experience bleeding secondary to atrophic changes of the vagina or endometrium. ${ }^{17}$ The American College of Obstetricians and Gynecologists has opined that in

Table 5 a: Accuracy of transvaginal ultrasound in detecting endometrial carcinoma compared with histopathology.

\begin{tabular}{lcccc}
\hline $\begin{array}{l}\text { Transvaginal ultrasound } \\
\text { findings }\end{array}$ & \multicolumn{2}{c}{ Histopathology (D\&C) } & Total & P value \\
\hline Cancer & CA & No CA & & 2 \\
No cancer & 2 & 0 & 53 & $1^{*}$ \\
Total & 1 & 52 & 55 & \\
\hline
\end{tabular}

*By McNemar test

Table 5b: Indicators for accuracy of ultrasound in detecting cancer compared with histopathology.

\begin{tabular}{lllll}
\hline Sensitivity & Specificity & PV positive & PV negative & Agreement \\
\hline $66.7 \%$ & $100 \%$ & $100 \%$ & $98.1 \%$ & $98.2 \%$ \\
\hline
\end{tabular}


postmenopausal women with bleeding when presented with a thin distinct endometrial echo on transvaginal ultrasonography of $4 \mathrm{~mm}$ or less has a risk of malignancy of 1 in 917 . Therefore, an endometrial biopsy is not required, and the most likely diagnosis in such cases is an atrophic endometrium. ${ }^{17}$ In this study, the second most common cause of postmenopausal bleeding was endometrial hyperplasia, whether simple or complex endometrial hyperplasia (27.3\%). Two cases were missed to be diagnosed correctly by ultrasound; first was a case of endometrial hyperplasia with atypia, and the second was a case of chronic endometritis. In the last case, the woman presented with one episode of vaginal bleeding. On vaginal sonography, the endometrium was irregular a vascular on color Doppler, and its thickness was $6.7 \mathrm{~mm}$. Our study revealed endometrial polyps in nine cases (16.36\%), and all polyps were pedunculated and fortunately single vascular stalk or feeding vessels easily recognized by vaginal ultrasound using color Doppler. The current study revealed two cases of endometrial carcinoma(3.6\%) in which the endometrial thicknesses were $13 \mathrm{~mm}$ and $11.6 \mathrm{~mm}$. In both cases, the endometrium was irregularly thickened, hypervascular, and in one case the endometrial-myometrial junction was not clear. On this basis, the endometrial carcinoma was suggested. These findings are in agreement with other studies like El-Mowafi et al. where out of 42 postmenopausal patients, 19 cases showed atrophic endometrium $(45.2 \%), 19 \%$ endometrial hyperplasia, $26.2 \%$ endometrial polyp,endometritis $(4.8 \%)$, endometrial carcinoma $(4.8 \%){ }^{17}$ Another study done by Sonali showed that out of 174 postmenopausal women suffering from uterine bleeding, $48.85 \%$ were endometrial atrophy, $9.77 \%$ polyp, $13.80 \%$ hyperplasia, $10.34 \%$ endometrial carcinoma and $5.75 \%$ hyperplasia with atepia. ${ }^{18}$ Another study done by Tsikouras et al. observed on 123 postmenopausal women with suspicious endometrium $>5 \mathrm{~mm}$, endometrial polyp was $7.13 \%$, one cervical polyp with extension in the cavity, endometrial atrophy was $73.1 \%$, atrophic endometritis was $8.13 \%$, hyperplasia was $1.62 \%$ and hyperplasia with atepia was $0.18 \%{ }^{19}$ Another study done in Turkey on women with uterine bleeding including pre and postmenopausal age group out of 244 women, $10.9 \%$ were polyp, endometritis $6.8 \%, 3.1 \%$ atrophic endometrium, $1.1 \%$ endometrial carcinoma. ${ }^{20}$ Another study done by Memon et al. on 112 postmenopausal women with uterine bleeding showed postmenopausal atrophic endometrium in $64(57.14 \%)$ patients, endometrial polyp in $5(4.16 \%)$ patients, endometrial hyperplasia in $27(24.10 \%)$ patients, endometrial carcinoma in 8 (7.14\%) patients, pyometra in four $(3.57 \%)$ patients and fibroid uterus in four $(3.57 \%)$ patients. ${ }^{21}$ While in the study done by Moradan et al., ${ }^{22}$ the reported results on transvaginal sonography were atrophy in $30(50 \%)$, hyperplasia in $13(21.66 \%)$, endometrial polyp in $16(26.66 \%)$ and carcinoma in one $(1.6 \%)$. Another study conducted by Sadoon et al. ${ }^{24}$ on 142 patients reported that the incidence of endometrial pathology was found to be of $23.9 \%$ and only $5 \%$ for endometrial carcinoma, also they found that benign endometrial pathologies are the most common cause of postmenopausal bleeding, this in agreement with our study. The current study revealed that the sensitivity of vaginal ultrasound for detection of endometrial carcinoma was $66.7 \%$, the specificity was $100 \%$, the predictive value (PV) positive was $100 \%$, and the PV negative was $98.1 \%$. The total agreement rate was $98.2 \%$. This is in comparison to a study done by Gull et al. that showed a sensitivity of $100 \%$, specificity of $60 \%$, positive predictive value of $25 \%$ and negative predictive value of $100 \%{ }^{24}$ However, Moradan et al. in their study in Iran on 60 women with postmenopausal bleeding revealed the sensitivity, specificity, positive and negative 
predictive values of transvaginal ultrasound in the diagnosis of uterine pathologies were $83.3 \%, 86.7 \%, 86.2$ and $83.9 \%$, respectively. ${ }^{22}$ Another study done in our locality in Erbil showed sensitivity and specificity of vaginal ultrasound in the detection of endometrial pathologies were $100 \%$ and $94.7 \%{ }^{25}$ Another study done by Showkat et al. showed a sensitivity of transvaginal ultrasound in the detection of endometrial carcinoma of $67 \%$, specificity $100 \%$, accuracy $98 \%$, positive predictive value $100 \%$ and negative predictive value $97 \% .^{26}$

\section{Conclusion}

Transvaginal sonographic scanning is gold slandered investigation for postmenopausal women with vaginal bleeding. It provides important information regarding uterine and endometrial pathologies. It also has an outstanding role in the detection of endometrial carcinoma to start necessary treatment depending on endometrial thickness. No women with endometrial thickness $\leq 5 \mathrm{~mm}$ were diagnosed as having endometrial cancer or endometrial pathology. A woman who has endometrial thickening and other positive findings on ultrasound, such as increased vascularity with color Doppler, in homogeneity of endometrium, particulate fluid, or thickened endometrium, should be further evaluated by endometrial biopsy. Also, we conclude that with the use of vaginal ultrasound we can reduce the number of patients requiring the endometrial biopsy depending on the ultrasound results whether further investigation is necessary with diagnostic curettage or other forms of endometrial biopsy.

\section{Competing interests}

The authors declare that they have no competing interests.

\section{References}

1. Breijer MC, Timmermans $A$, van Doorn HC, Mol BWJ, Opmeer BC. Diagnostic Strategies for Postmenopausal Bleeding. Obstet Gynecol Int 2010; 2010:850812.
2. Menopause: Overview. Eunice Kennedy Shriver National Institute of Child Health and Human Development. 28 June, 2013. (Accessed on October 11, 2017, at https://.www.nichd.nih.gov/ health/topics/menopause/Pages/default.aspx).

3. Munot S, Lane G. Modern management of postmenopausal bleeding. Trends Urology, Gynecol. Sexual Health 2008; 13:20-4.

4. Moodley M, Roberts C. Clinical pathway for the evaluation of postmenopausal bleeding with an emphasis on endometrial cancer detection. J Obstet Gynaecol 2004 ; 24(7):736-41.

5. Astrup K, Olivarius NDF. Frequency of spontaneously occurring postmenopausal bleeding in the general population. Acta Obstet Gynecol Scand 2004; 83(2):203-7.

6. Nalaboff KM, Pellerito JS, Ben-Levi E. Imaging the endometrium: disease and normal variants. Radio graphics 2001; 21:1409-24.

7. Clark TJ, Barton PM, Coomarasamy A, Gupta JK, Khan KS. Investigating postmenopausal bleeding for endometrial cancer: cost-effectiveness of initial diagnostic strategies. BJOG 2006; 113(5) 502-10.

8. Sanders RC, Winter TC. Clinicalsonography a practical guide. $4^{\text {th }}$ ed. LWW; 2007. P. 313-4.

9. Smith-Bindman R, Weiss E, Feldstein V; How thick is too thick? When endometrial thickness should prompt biopsy in postmenopausal women without vaginal bleeding. Ultrasound Obstet Gynecol 2004; 24(5):558-65.

10. Sahdev A. Imaging the endometrium in postmenopausal bleeding. BMJ 2007; 334 (7594):635-6.

11. Gerber B, Krause A, Muller H, Reimer T, Kulz T, Makovitzky J, et al. Effects of adjuvant tamoxifen on the endometrium in postmenopausal women with breast cancer: a prospective long-term study using transvaginal ultrasound. J Clin Oncol 2000; 18:3464-70.

12. Otify M, Fuller J, Ross J, Shaikh H, Johns J. Endometrial pathology in the postmenopausal woman - an evidence based approach to management. TOG 2015; 17(1):29-38.

13. Timmerman D, Verguts J, Konstantinovic ML, Moerman P, Van Schoubroeck D, Deprest J, et al. The pedicle artery sign based on sonography with color Doppler imaging can replace second-stage tests in women with abnormal vaginal bleeding. Ultrasound Obstet Gynecol 2003; 22:166-71.

14. Parkin DM, Bray F,Ferlay J, PisaniP. Estimating the world cancer burden: Globocan 2000. Int J Cancer 2001; 94(2):153-6.

15. Timmermans A, Opmeer BC, Veersema S, Mol BW. Patient performances in the evaluation of the postmenopausal bleeding. BJOG 2007; 114(9):1146-9.

16. El-Mowafi D, Farid A, El-Badawi A. Transvaginalsonography and Hysterescopy Versus Histopathology in postmenopausal 
Bleeding Obstetrics and Gyenecology, Radiology and Pathology Departments, Benha Faculty of Medicine Egypt 2005. (Accessed November 11, 2017 , at https://www.gfmer.ch/ International_activities_En/EI_Mowafi/ Transvaginal_sonography.htm).

17. ACOG Committee Opinion No. 440: The Role of Transvaginal Ultrasonography in the Evaluation of Postmenopausal Bleeding. Obstet Gynecol 2009; 114(2):409-11

18. Sonali R, Sangeeta K , Manisha K . Histopathological evaluation in women with postmenopausal bleeding and associated risk factors for endometrial carcinoma. JEMDS 2013; I2(24):4397-02

19. Tsikouras P, Galazios G, Liberis V, Bouzaki A, Grapsas X, Maroulis G. TV sonographic assessment in postmenopausal asymptomatic women. Eur J Gynaecol Oncol 2007; 28(6):4736.

20. Ozer A, Ozer S, Kanat-Pektas M. Correlation between transvaginal ultrasound measured the endometrial thickness and histopathological findings in Turkish women with abnormal uterine bleeding. J Obstet Gynaecol 2016; 42(5):573-8.

21. Memon F, Munwar R Rajpar S, Shoukat R, Sikandar R. Postmenopausal uterine bleeding; correlation of the findings of transvaginal ultrasonography \& endometrial sampling in patient. Professional Med J 2016; 23(12):1471-6.

22. Moradan SA, Ghorbani RB, Far MFC. Does transvaginal ultrasonography have good diagnostic value in endometrial pathology? Inter Medical J Malaysia 2011; 10(2):17-20

23. Sadoon S, Salman G, Smith G, Henson C, MacCollough W. Ultrasonographic endometrial thickness for diagnosing endometrial pathology in postmenopausal bleeding. J Obstet Gynecol 2007; 27(4):406-8.

24. Gull B, Karlsson B, Milsom I, Granberg S. Can ultrasound replace dilatation and curettage? A longitudinal evaluation of postmenopausal bleeding and transvaginalsonographic measurement of endometrial cancer. Am J Obstet Gynecol; 2003; 188:401-8.

25. Sedeq MS, Muhammed PR, ShekhMuhammed SS, Alalaf SK. A prospective comparison of transvaginal, transabdominal ultrasound and diagnostic curettage in the evaluation of endometrial pathology in Erbil. Zanco J Med Sci 2016; 20(1):1206-12.

26. Showkat MS, Nabi S, Khondker L, Bhowmik B, Tushar SN, Jahan MU. Role of transvaginalsonography in the detection of endometrial carcinoma. Bangladesh Med Res Counc Bull 2013; 39(2): $\overline{80}-5$. 